\title{
Combining morphology, scanning electron microscopy, and molecular phylogeny to evaluate the taxonomic power of scales in genus Aphanius Nardo, 1827 (Teleostei: Cyprinodontidae)
}

\author{
Azad Teimori, Mina Motamedi, Mahbubeh Shaker Golmakan
}

Received - 19 March 2017/Accepted - 13 June 2017. Published online: 30 June 2017; @Inland Fisheries Institute in Olsztyn, Poland Citation: Teimori A., Motamedi M., Golmakan M.S. 2017 - Combining morphology, scanning electron microscopy, and molecular phylogeny to evaluate taxonomic power of scales in the genus Aphanius Nardo, 1827 (Teleostei: Cyprinodontidae) - Arch. Pol. Fish. $25: 77-87$.

\begin{abstract}
Scale morphology and its structural details were studied with morphometry, geometric morphometrics, and scanning electron microscopy in five Iranian Aphanius species and examined comparatively with molecular phylogeny. Scales were cycloid and circular in A. farsicus Teimori, Esmaeili \& Reichenbacher and A. vladykovi Coad, cycloid and polygonal in $A$. isfahanensis Hrbek, Keivany \& Coad and A. sophiae (Heckel), and were spined and polygonal in $A$. dispar Rüppell. Univariate analysis indicated that the relative length of anterior margin of radii played a significant role in the separation of some species studied $(\mathrm{P}<0.05)$. Canonical Variates Analysis (CVA) based on seven landmarks showed clear separation between the Iranian inland and inland-related Aphanius species (IIRAS) group (four species) and the brackish water species (A. dispar). The lepidonts were conical in the IIRAS group with the exception of $A$. isfahanensis (rounded) and were rounded in A. dispar. Based on the basal position of the brackish water Aphanius species in the phylogenetic trees of the genus Aphanius, it can be assumed that the presence of rounded lepidonts was a primary state in their scales or is the result of convergent evolution. Also, the polygonal state in the scales of Aphanius species was a primitive shared character state.
\end{abstract}

Keywords: Cyprinodontiformes, lepidont, phylogeny, scale topology, geometric morphometrics, Iran

\footnotetext{
A. Teimori [ $\risingdotseq]$, M. Motamedi, M.S. Golmakan

Department of Biology, Faculty of Sciences

Shahid Bahonar University of Kerman, Iran

e- mail: azad.teimori@gmail.com; a.teimori@uk.ac.ir
}

\section{Introduction}

Iran is known as speciation center for the members of the genus Aphanius Nardo 1827. To date, 14 species have been reported from this country, of which 12 are endemic (Hrbek et al. 2006, Coad 2009, Esmaeili et al. 2014, Gholami et al. 2014, Teimori et al. 2012a, 2014, 2016). Although these species are clearly distinguishable by genetic markers, most of them are similar in their external morphology. Therefore, in addition to the use of molecular markers in recent years (e.g., Hrbek et al. 2006, Esmaeili et al. 2014, Gholami et al. 2014, Teimori et al. 2014), other tools, including fish anatomy and hard structures, have been used for species identification (Gholami et al. 2014, Teimori et al. 2014) and even population discrimination (Gholami et al. 2013).

A few studies have already been addressed the power of the scale morphology in the classification of Aphanius species and also in understanding of population variation (e.g., Ferrtito et al. 2009, Gholami et al. 2013). In the current research, we used four data sets, including scale morphometric variables, geometric morphometric landmarks, scanning electron microscopy, and molecular sequences. We focused our questions on the most relevant characteristics of scale topology and scalar denticles (lepidonts) to

(c) Copyright by Stanisław Sakowicz Inland Fisheries Institute in Olsztyn.

(c) 2017 Author(s). This is an open access article licensed under the Creative Commons Attribution-NonCommercial-NoDerivs License (http://creativecommons.org/licenses/by-nc-nd/3.0/). 
complete the previous studies and to garner further knowledge on the taxonomic significance of scale morphology in the genus Aphanius. We discuss whether variation related to the structural details of scale morphology contain taxonomic and even phylogenetic information in the Iranian Aphanius species. curling, mounted dorsal-side-up on Scanning Electron Microscopy (SEM) stubs with double self-adhesive carbon stickers, and coated with an $100 \AA$ A-thick gold layer using a Polaron E 5100. Five to twelve images per scale were captured with a LEO $1430 \mathrm{VP}$ at $15 \mathrm{kV}$. These images were used to study the scalar denticles (lepidonts).

\section{Materials and methods}

This study considers five Iranian Aphanius species i.e., four endemic species belong to the Iranian inland and inland-related Aphanius species (IIRAS, group 1 in figure 1a-c) and include Aphanius farsicus from the Maharlu Lake Basin, A. isfahanensis from the Esfahan Basin, A. sophiae from the Kor River Basin, and A. vladykovi from the Tigris Basin, and a single native species, A. dispar, from the Hormuzgan Basin in Southern Iran, which is a brackish water member (group 2 in figure 1e) (Esmaeili et al. 2014).

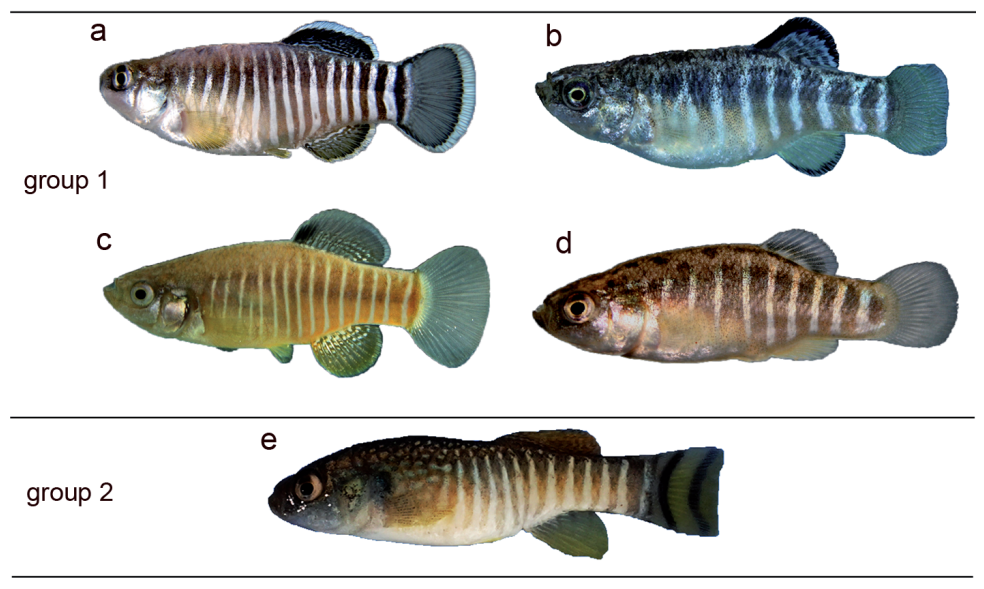

Figure 1. Photographs showing the studied Iranian inland and inland related Aphanius species, IIRAS (a-d) and brackish water groups (e). a to d refer to $A$. farsicus, $A$. isfahanensis, $A$. sophiae and A. vladykovi respectively; and e refers to A. dispar.

\section{Scale extraction and examination}

The fish scales from the third to fourth rows between the dorsal fin and the lateral line were removed from the left side of the specimens (Fig. 2a). These are considered to be "key scales" (Johal et el. 2006). The scales were immediately rinsed in distilled water, cleaned mechanically to remove irrelevant matter using a fine brush, and transferred into a $1 \% \mathrm{KOH}$ solution for 40 minutes to remove soft tissues from the surface. Twenty scales per species were imaged with a digital camera connected to a Leica compound microscope taken at $15 \mathrm{x}$ magnification. These were used for both morphometric and geometric morphometric analyses.

The cleaned scales were dehydrated through an ascending ethanol series (30, 50, 70, and 90\%) at 30 minute intervals (Lippitsch 1990), dried on Whatman filter paper, kept for several hours between two glass slides to prevent scale margin

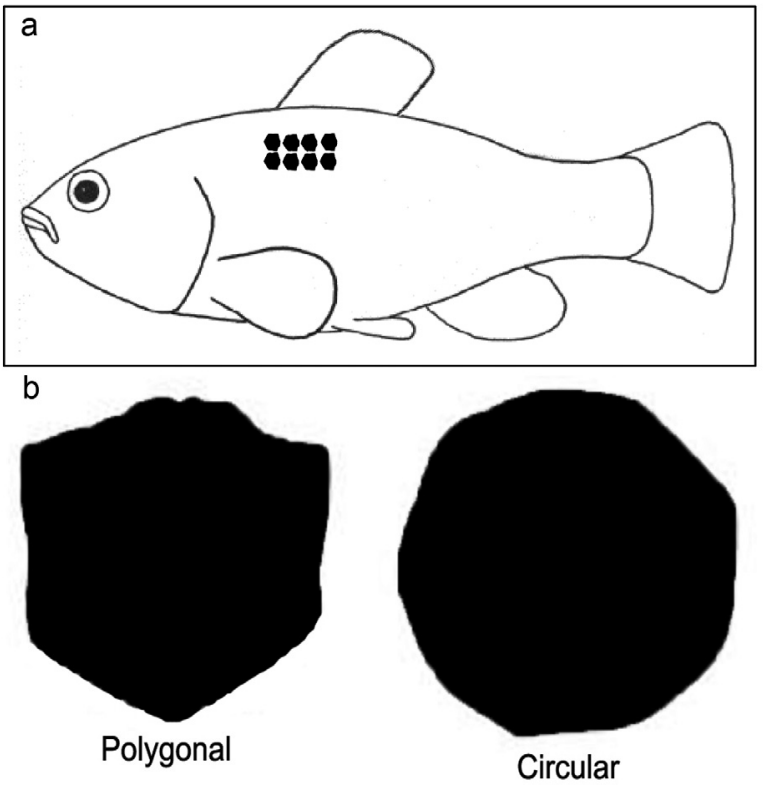

Figure 2. (a) Left side of the fish specimen shows location between the dorsal fin and lateral line, where the key scales were removed; (b) two main scale types distinguished in this study. 
Table 1

Five studied linear measurements of scales. They were standardized with the following equation: $(($ scale character $\times 100) / \mathrm{x}$ where, $x=$ DVL, APL, AMR, or PMR). Finally, ten standardized variables were prepared for statistical analyses. In addition, the focal index (Fi index) was calculated as $\left(\mathrm{a}-\mathrm{f}^{\prime} / \mathrm{a}-\mathrm{a}^{\prime}\right) \times 100$. See also Figure 3 for details of the characters. APL - anterior-posterior length; DVL - dorsal-ventral height; PMR - length of the posterior margin of the radii; AMR - length of the anterior margin of the radii; $\mathrm{RL}$ - length of the first radius

\begin{tabular}{|c|c|c|c|}
\hline Character & Measurement & Standardized variable & Description \\
\hline APL & $a-a^{\prime}$ & & \\
\hline DVL & $b-b^{\prime}$ & DVL.APL & $\left(b-b^{\prime} / a-a^{\prime}\right) \times 100$ \\
\hline \multirow[t]{2}{*}{ PMR } & $\mathrm{c}-\mathrm{c}^{\prime}$ & PMR.DVL & $\left(c-c^{\prime} / b-b^{\prime}\right) \times 100$ \\
\hline & & PMR.APL & $\left(c-c^{\prime} / a-a^{\prime}\right) \times 100$ \\
\hline \multirow[t]{3}{*}{ AMR } & $d-d^{\prime}$ & AMR.DVL & $\left(d-d^{\prime} / b-b^{\prime}\right) \times 100$ \\
\hline & & AMR.APL & $\left(d-d^{\prime} / a-a^{\prime}\right) \times 100$ \\
\hline & & AMR.PMR & $\left(d-d^{\prime} / c-c^{\prime}\right) \times 100$ \\
\hline \multirow[t]{4}{*}{$\mathrm{RL}$} & $e-e^{\prime}$ & RL.DVL & $\left(e-e^{\prime} / b-b^{\prime}\right) \times 100$ \\
\hline & & RL.APL & $\left(e-e^{\prime} / a-a^{\prime}\right) \times 100$ \\
\hline & & RL.AMR & $\left(e-e^{\prime} / d-d^{\prime}\right) \times 100$ \\
\hline & & RL.PMR & $\left(e-e^{\prime} / c-c^{\prime}\right) \times 100$ \\
\hline Fi index & $a-f^{\prime}$ & $a-f^{\prime} / a-a^{\prime}$ & $\left(a-f^{\prime} / a-a^{\prime}\right) \times 100$ \\
\hline
\end{tabular}

\section{Scale description and morphometry, and calculating the focal index}

The scale terminology follows Bräger (2016). Five linear measurements were recorded using ImageJ software (Schneider et al. 2012) as follows; anterior-posterior length (APL); dorsal-ventral height (DVL); length of the posterior margin of the radii (PMR); the length of the anterior margin of the radii (AMR); and the length of the first radius (RL) (Fig. 3). To remove the effects of allometry on scale shape, all measurements were standardized with the following equation: $(($ scale character $\times 100) / x$, where, $x=$ DVL, APL, AMR, or PMR, see Table 1). Finally, ten standardized variables were prepared for statistical analyses. The Shapiro-Wilk test showed normal distribution for the data set $(\mathrm{P}>0.05)$. Therefore, univariate analysis, ANOVA with the post hoc test was used to show the significance of differences among the species, and Canonical Discriminant Analysis (CDA) was used to show the correct classification of the studied species. The Single Linkage (nearest neighbor) method was also used to determine hierarchical clustering in our

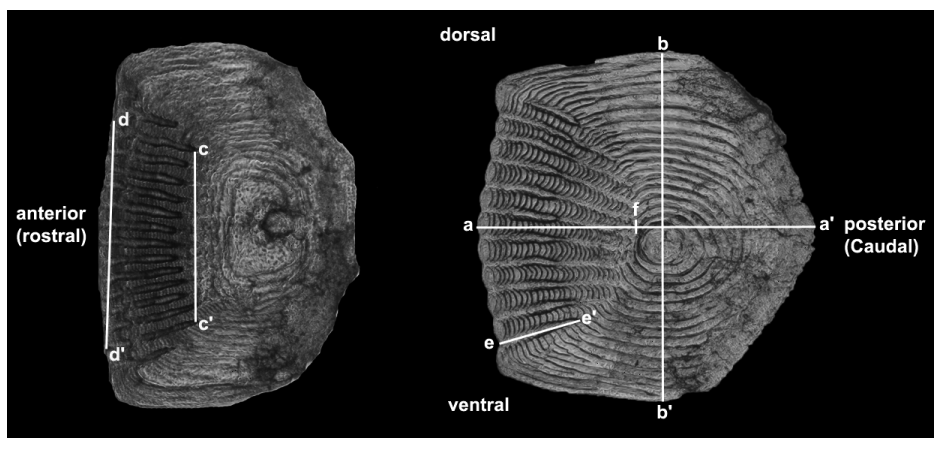

Figure 3. The linear measurements used for the morphometric analyses and also calculating of the focal index $(\mathrm{Fi})$ as $\left(\mathrm{a}-\mathrm{f} / \mathrm{a}-\mathrm{a}^{\prime}\right) \times 100$. Anterior-posterior length (APL), dorsal-ventral height (DVL), length of posterior margin of radii (PMR), length of anterior margin of the radii (AMR), and the length of first radius (RL). "a-f" is the distance from the outermost part of the anterior field to the focus, and " $\mathrm{a}-\mathrm{a}$ "” is the distance from the outermost part of the anterior field to the outermost part of the posterior field (Bräger 2016). 
multivariate data sets, in which clusters were joined based on the smallest distance between two groups.

Moreover, the focal index (Fi index) was calculated to estimate the geometrical position of the focus in the studied scales as follows: $\left(\mathrm{a}-\mathrm{f} / \mathrm{a}-\mathrm{a}^{\prime}\right) \times 100$, where "a-f" was the distance from the outermost part of the anterior field to the focus and " $\mathrm{a}-\mathrm{a}$ '" was the distance from the outermost part of the anterior field to the outermost part of the posterior field (Fig. 3, see Table 1). Accordingly, the position of the focus was determined as follows: $\mathrm{Fi}<0.20$ was the anterior position; 0.21-0.40 was the antero-central position; $0.41-0.60$ was the central position; $0.61-0.80$ was the postero-central position; $>0.81$ was the posterior position (Bräger 2016). All analyses were performed in IBM SPSS version 22 and PAST (PAleontological Statistics, Hammer 2001).

\section{Geometric morphometric analysis (GMA)}

Here we used the same scales as before for the linear morphometric analysis. The shapes of the scale were analysed using landmark-based geometric morphometric methods (Zelditch et al. 2004). To do this, the digital images were first compiled using TpsUtil v. 1.58 (Rohlf 2015) software. According to Ibanez et al. (2007) and Requieron et al. (2012), seven landmarks were defined on each scale with tpsDig2 (Rohlf 2013) as follow (see also Fig. 4):

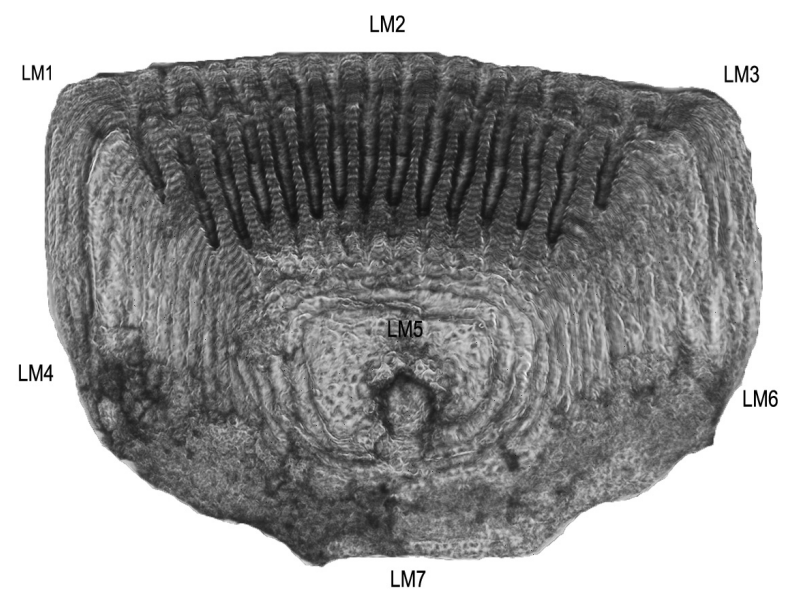

Figure 4. Landmarks used to define the shape of the scales (tooth-carp). The areas of the scales are described with respect to the fish position.
Landmark 1: the left lateral tip of the anterior portion of the scale

Landmark 2: the center of the anterior edge of the scale

Landmark 3: the right lateral tip of the anterior portion of the scale

Landmark 4: the left boundary between the anterior area with circuli and the posterior area Landmark 5: the focus of the scale Landmark 6: the right boundary between the anterior area with circuli and the posterior area Landmark 7: the tip of the posterior portion of the scale.

The MorphoJ software package was used for further analysis (Klingenberg 2011). Generalized Least-squares Procrustes Superimposition (GLS) was applied to the coordinates of raw landmarks to the scales to translate and rotate them and to get new shape variables, independent of scale size (Rohlf 1990). Canonical Variates Analysis (CVA) and Discriminant Function Analysis (DFA) were performed to examine group separation. Permutation testing was performed (10000 iterations) to test the reliability of the results. To evaluate the overall pattern of morphometric relationships among the five studied species, UPGMA cluster analysis was performed on the matrix of shape distances (Euclidean Distances) using PAST (PAlaeontological Statistics, v.1.81 (Hammer et al. 2001). Moreover, Mahalanobis distance $(\mathrm{P}<0.0001)$ was applied to show the significance of mean shape among the populations compared.

\section{Maximum likelihood phylogenetic analysis}

The maximum likelihood phylogenetic (ML) analysis is based on 15 mitochondrial cytb sequences that were deposited in Genbank by the first author (Teimori et al. 2012a, Esmaeili et al. 2014). The accession numbers of the examined sequences are as follows: A. farsicus (KF910701-KF910704); A. isfahanensis (JX154887-JX154889 and JN565969); $A$. sophiae (KJ634203-KJ634206); A. vladykovi (JN547802-JN547803); and A. dispar (JN547798). 
The sequences were aligned using Muscle 3.6 (Edgar 2004), as incorporated in Seaview version 4.6.1 (Gouy et al. 2010). The ML analysis was performed using RaxML 7.2.6 (Stamatakis 2006) under the most complex GTR+G+I model of nucleotide substitution, with 2000 bootstrap replicates.

\section{Results}

\section{Topology of the scales}

The studied scales were divided into four parts: rostral and caudal fields and ventral and dorsal sides (Fig. 3). Scales imbricate each other, so only the caudal field was exposed and visible on the surface, while the rostral field lay embedded in the dermis.

Considering scale topology, two main scale types were distinguished as follows: circular (scales without additional separate ossifications) and polygonal (multi-sided forms with somehow square outline with angled corners) (Fig. 2b). In addition, the scales were classified according to the pattern on the outer edge where cycloid scales have a smooth outer edge and spined scales have spinous-like structures on the outer edge. Accordingly, scales were cycloid and circular in A. farsicus and A. vladykovi, cycloid and polygonal in $A$. isfahanensis and A. sophiae, and spined and polygonal in A. dispar (Fig. 5).

Three types of radii were present in the studied scales. Alternatively, two or all three types could be found in the scales of one species. In the rostral field of the scales, some radii failed to develop completely from the focus area (secondary radii). Therefore, the circuli remained uninterrupted in that part of the scale (originating midway between the focus and the margin). Also, some radii originated between the midway and the margin of the scale and were regarded as "tertiary radii".

Both types of radii (secondary and tertiary) are present in the scales studied in A. farsicus and $A$. isfahanensis. In the scales of $A$. sophiae and $A$. vladykovi, the radii were secondary and tertiary types, with secondary radii the most common type. In

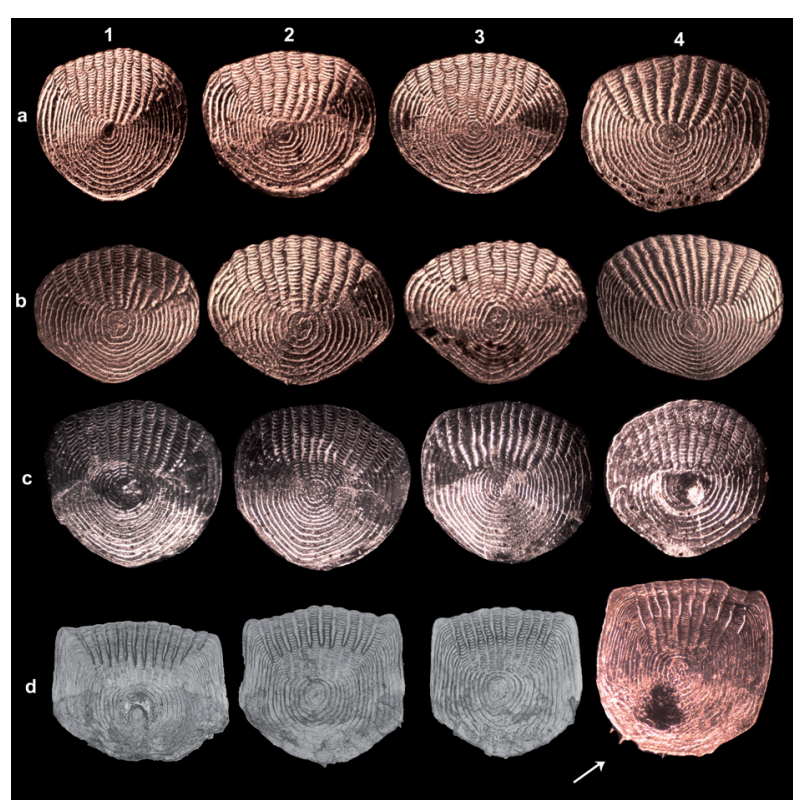

Figure 5. Photographs of light microscopy (LM) show general morphology of scales in the studied Aphanius species. a to d refer to $A$. farsicus, $A$. isfahanensis, $A$. sophiae and A. vladykovi respectively; and e refers to $A$. dispar. The arrow indicates spinous-like structures in the most posterior edge of the scales in $A$. dispar.

the rostral field of the scales in A. dispar, the continuity of the circuli was often interrupted by the primary radii. Secondary radii were also present, while primary radii were the most common type (Fig. 5).

As mentioned above, the position of the focus varied among the scales of the species studied. Based on the focal index, the focus in $A$. farsicus was rounded and positioned centrally $(\mathrm{Fi}=0.46)$. In $A$. isfahanensis it was semicircular and positioned in the antero-central part of the scale $(\mathrm{Fi}=0.40)$. In $A$. sophiae it was oblong and positioned in the antero-central part of the scale $(\mathrm{Fi}=0.35)$. In $A$. vladykovi it was semicircular and positioned centrally $(\mathrm{Fi}=0.51)$. In A. dispar it was oblong and positioned centrally $(\mathrm{Fi}=0.41)$.

\section{Morphometric analyses}

The results of descriptive analysis of scale variables are summarized in Table 2. Morphometric analysis was based on ten standardized scale variables. Univariate analysis shows that four of the ten morphometric characters (AMR.DVL, AMR.APL, 
Table 2

Descriptive analysis (mean \pm SD) of scale variables. Mean value of characters that are significantly different are indicated with an asterisk. SD - standard deviation, min - minimum, max - maximum. See also Figure 3 for details of the characters

\begin{tabular}{|c|c|c|c|c|c|}
\hline \multirow[b]{3}{*}{ Character } & \multirow{2}{*}{$\begin{array}{l}\text { Brackish water species } \\
\text { A. dispar }\end{array}$} & \multicolumn{4}{|c|}{ Inland and inland related Aphanius species (IIRAS) } \\
\hline & & A. farsicus & A. isfahanensis & A. sophiae & A. vladykovi \\
\hline & $\begin{array}{l}\text { Mean } \pm \text { SD } \\
(\min -\max )\end{array}$ & $\begin{array}{l}\text { Mean } \pm \text { SD } \\
(\min -\max )\end{array}$ & $\begin{array}{l}\text { Mean } \pm \text { SD } \\
(\min -\max )\end{array}$ & $\begin{array}{l}\text { Mean } \pm \text { SD } \\
(\text { min-max })\end{array}$ & $\begin{array}{l}\text { Mean } \pm \text { SD } \\
(\min -\max )\end{array}$ \\
\hline AMR.DVL & $\begin{array}{l}69.7 * \pm 5.6 \\
(60.6-76.5)\end{array}$ & $\begin{array}{l}81.1 \pm 3.9 \\
(71.7-87.3)\end{array}$ & $\begin{array}{l}78.1 \pm 5.5 \\
(70.4-93.5)\end{array}$ & $\begin{array}{l}79.3 \pm 8.4 \\
(64.5-90.5)\end{array}$ & $\begin{array}{l}77.2 \pm 7.5 \\
(72.3-84.6)\end{array}$ \\
\hline PMR.DVL & $\begin{array}{l}51.9 \pm 11.7 \\
(32.2-71.1)\end{array}$ & $\begin{array}{l}56.4 \pm 6.5 \\
(40.4-78.5)\end{array}$ & $\begin{array}{l}53.0 \pm 12.4 \\
(42.4-71.1)\end{array}$ & $\begin{array}{l}53.2 \pm 9.4 \\
(44.0-66.4)\end{array}$ & $\begin{array}{l}55.3 \pm 8.0 \\
(45.0-68.6)\end{array}$ \\
\hline RL.DVL & $\begin{array}{l}20.1 \pm 4.1 \\
(11.1-26.6)\end{array}$ & $\begin{array}{c}15.3 \pm 3.1 \\
(9.1-19.8)\end{array}$ & $\begin{array}{l}20.8 \pm 3.4 \\
(10.4-26.3)\end{array}$ & $\begin{array}{l}24.0 * \pm 4.9 \\
(10.7-40.4)\end{array}$ & $\begin{array}{l}17.2 \pm 9.1 \\
(12.3-21.6)\end{array}$ \\
\hline AMR.APL & $\begin{array}{l}74.4^{*} \pm 8.1 \\
(66.6-94.4)\end{array}$ & $\begin{array}{l}96.2 \pm 6.3 \\
(89.6-111.5)\end{array}$ & $\begin{array}{l}83.6 \pm 7.4 \\
(72.6-96.5)\end{array}$ & $\begin{array}{l}82.6 \pm 8.1 \\
(69.6-105.9)\end{array}$ & $\begin{array}{l}97.2 \pm 11.5 \\
(92.2-112.5)\end{array}$ \\
\hline PMR.APL & $\begin{array}{l}55.5 \pm 13.1 \\
(33.1-77.1)\end{array}$ & $\begin{array}{l}66.1 \pm 10.2 \\
(51.5-89.8)\end{array}$ & $\begin{array}{l}56.7 \pm 14.1 \\
(45.6-76.5)\end{array}$ & $\begin{array}{l}55.3 \pm 9.6 \\
(42.1-73.1)\end{array}$ & $\begin{array}{l}70.2 \pm 0.6 \\
(55.3-88.1)\end{array}$ \\
\hline RL.APL & $\begin{array}{l}21.4 \pm 4.4 \\
(10.8-26.4)\end{array}$ & $\begin{array}{l}18.9 \pm 4.3 \\
(10.7-25.0)\end{array}$ & $\begin{array}{l}21.2 \pm 4.3 \\
(11.7-30.0)\end{array}$ & $\begin{array}{l}25.2 \pm 5.5 \\
(11.5-50.7)\end{array}$ & $\begin{array}{l}21.3 \pm 11.2 \\
(16.5-25.0)\end{array}$ \\
\hline RL.AMR & $\begin{array}{l}28.9 \pm 6.1 \\
(16.0-30.0)\end{array}$ & $\begin{array}{l}19.7 \pm 4.7 \\
(10.7-26.6)\end{array}$ & $\begin{array}{l}25.7 \pm 4.7 \\
(12.7-36.6)\end{array}$ & $\begin{array}{l}30.5 \pm 6.7 \\
(12.4-47.3)\end{array}$ & $\begin{array}{l}22.9 \pm 11.6 \\
(15.0-28.3)\end{array}$ \\
\hline RL.PMR & $\begin{array}{l}40.2 \pm 12.5 \\
(28.5-70.0)\end{array}$ & $\begin{array}{l}30.1 \pm 9.9 \\
(12.6-45.3)\end{array}$ & $\begin{array}{l}38.1 \pm 9.9 \\
(15.6-52.3)\end{array}$ & $\begin{array}{l}47.9 \pm 11.6 \\
(15.0-81.1)\end{array}$ & $\begin{array}{l}31.8 \pm 8.2 \\
(20.8-46.8)\end{array}$ \\
\hline AMR.PMR & $\begin{array}{l}140.3 \pm 20.2 \\
(107.4-200.0)\end{array}$ & $\begin{array}{l}148.8 \pm 20.6 \\
(112.0-178.5)\end{array}$ & $\begin{array}{l}151.8 \pm 20.6 \\
(113.0-183.5)\end{array}$ & $\begin{array}{l}150.1 \pm 20.3 \\
(128.6-181.3)\end{array}$ & $\begin{array}{l}141.8 \pm 19.6 \\
(108.6-173.8)\end{array}$ \\
\hline DVL.APL & $\begin{array}{l}106.6 \pm 7.9 \\
(97.0-125.0)\end{array}$ & $\begin{array}{l}119.5 \pm 8.4 \\
(107.8-131.2)\end{array}$ & $\begin{array}{l}106.5 \pm 8.4 \\
(100.8-119.2)\end{array}$ & $\begin{array}{l}103.2 \pm 5.8 \\
(90.0-122.1)\end{array}$ & $\begin{array}{l}126.7^{*} \pm 9.6 \\
(117.5-133.2)\end{array}$ \\
\hline
\end{tabular}

RL.DVL, DVL.APL) differed significantly among the species (ANOVA with the post hoc Duncan test, $\mathrm{P}<$ 0.05). Characters AMR.DVL and AMR.APL significantly separated $A$. dispar from all the studied members of the IIRAS group including; $A$. farsicus, $A$. isfahanensis, A. sophiae, and A. vladykovi. Also, within the IIRAS group, RL.DVL and DVL.APL significantly separated $A$. sophiae and A. vladykovi from the other relatives, respectively (ANOVA with the post hoc Duncan test, $\mathrm{P}<0.05$ ) (Table 2). Canonical Discriminant Analysis (CDA) was based on all ten scale morphometric characters. The result indicated separation between the brackish water species $(A$. dispar) and the IIRAS group; however, there was still some overlap between them (Fig. 6).

The average linkage dendrogram based on $\mathrm{Eu}-$ clidean distance was calculated for all ten scale characters. The resulting dendrogram categorized studied Aphanius species into two major clusters including "brackish water" and "IIRAS" (see the left side in Fig. 7). The brackish water cluster containes A. dispar, which was positioned as a basal cluster, and the IIRAS cluster containes the four other species. 


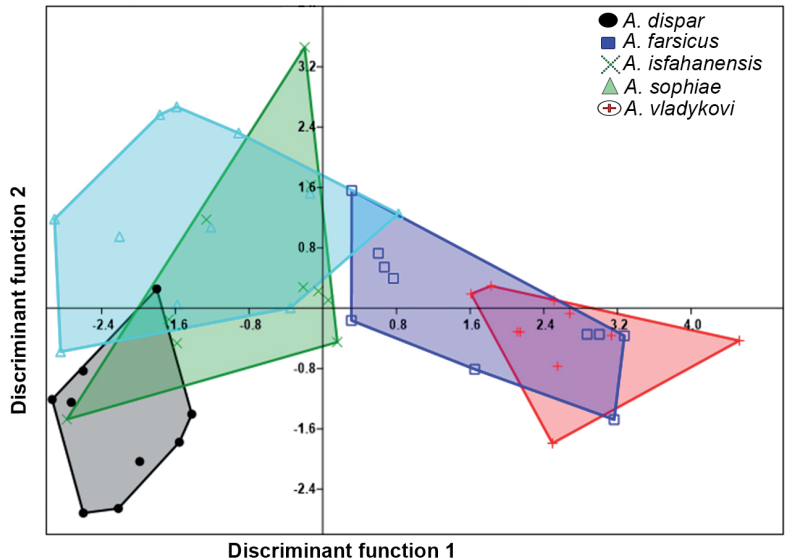

Figure 6. Canonical Discriminant Analysis (CDA) based on the ten morphometric characters of scales.

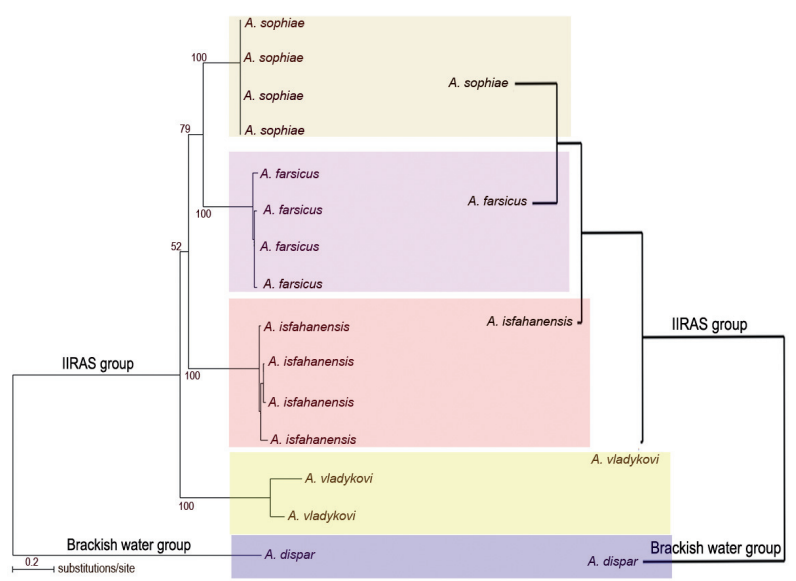

Figure 7. Maximum likelihood analysis based on the 15 cytochrome $b$ sequences estimates phylogenetic relationships of the studied Aphanius species (left side), and the average linkage dendrogram based on the ten morphometric characters of scales (right side).

\section{Geometric morphometric analyses}

The mean scale shape among the four endemic Iranian inland and inland-related Aphanius species (IIRAS) and a native brackish water species, A. dispar, showed no overlap in CVA $(\mathrm{P}<0.001)$. The four endemic Aphanius species could also be distinguished from each other with high reliability $(\mathrm{P}<$ 0.0001). The species were clearly separated with significantly different group means. Mahalanobis distance among the five species indicated high reliability based on the permutation test $(\mathrm{P}<0.001)$. CVA showed that the first two CVs captured 61.67, and $25.98 \%$ of the total shape variation, respectively. The general pattern of morphological differences described by these first two CVs was explored using transformation grids (Fig. 8a).

Shape changes associated with CV1 and CV2 were mainly due to the change in the left and right lateral tips of the anterior portion (LMs 1 and 3) and focus of the scale (LM5), while the shape changes associated with CV2 were mainly related to all of the landmarks with the exception of LMs 1 and 5 .

In the UPGMA analyses, two major clusters were identified. The first cluster contained a single species of the brackish water group, $A$. dispar. The second cluster contained the four species of the IIRAS group. In the second cluster $A$. sophiae formed a sister group
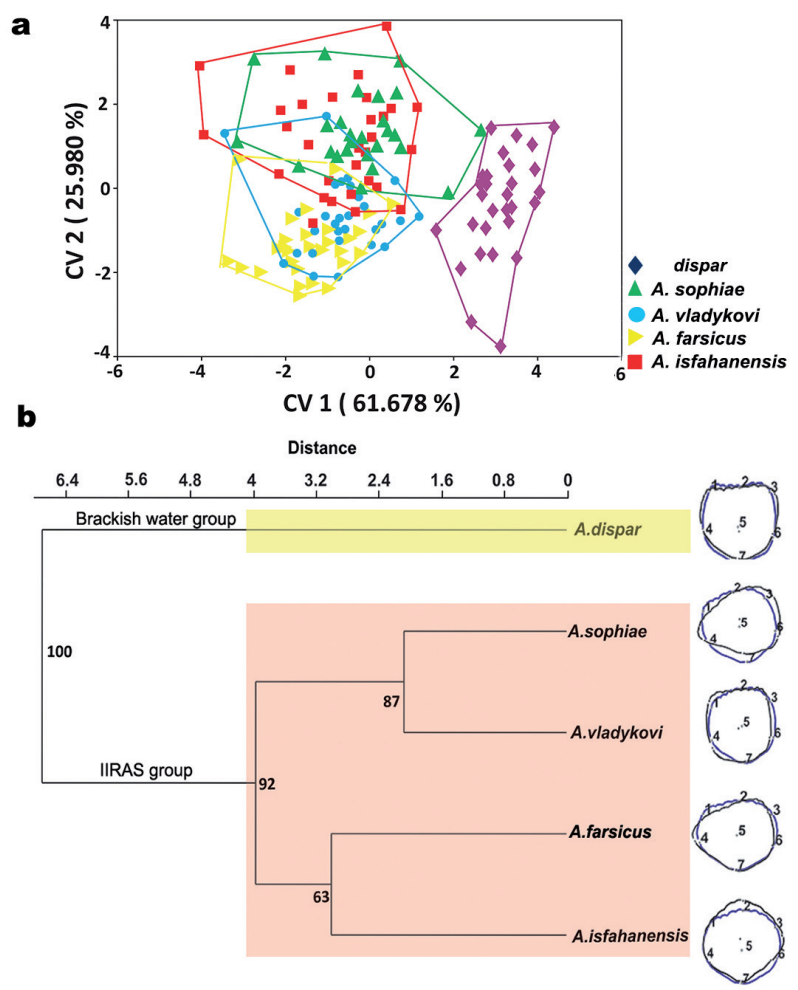

Figure 8. (a) Canonical Variate Analysis of the studied Aphanius species with landmark-based geometric morphometrics based on scale shape. General pattern of morphological differences described by the first two CVs was explored using transformation grids. The CV1 explained 61.67, and CV2 explained $25.98 \%$ of total shape variation respectively. (b) UPGMA cluster analysis performed on the matrix of shape distances (Euclidean Distances). Mean shape of scale based on the seven selected landmarks is shown for each species. 
with $A$. vladykovi, and these together were a sister to another cluster containing $A$. farsicus plus $A$. isfahanensis (Fig. 8b).

\section{Scanning electron microscopy (SEM)}

The scanning electron microscopic investigation showed that there were tooth-like microscopic processes in the circuli of the rostral and lateral fields that can be seen only under high magnification and are known as "scalar denticles." These structures are usually distributed in minute or crowded spaces. The density of denticles was higher in the rostral field than the older circuli in the lateral field. The denticles also varied in shape. In the lateral field itself, the denticles were well developed in the anterior part, while they gradually reduced and disappeared in the most posterior parts. The comparative results on scalar denticles are as follows:

Aphanius farsicus - the scalar denticles were present in both the interradial space of the rostral and the anterior part of the lateral fields. The interradial denticles were spaced. Considering their morphology, the denticles were short and conical in both the rostral and lateral fields (Fig. 9a).

Aphanius isfahanensis - the scalar denticles were crowded, short, and rounded and tapered in the rostral field (Fig. 9b), while they were often short and rounded in the lateral fields (a few were long and conically pointed).

Aphanius sophiae - the scalar denticles were moderately spaced, short, and conical in the rostral filed. They were moderately spaced and conical in the lateral fields (Fig. 9c).

Aphanius vladykovi - the scalar denticles were moderately spaced and long and conically pointed in the rostral field. In the lateral fields, they often disappeared, and, if present, they were conical (Fig. 9d). Aphanius dispar - the scalar denticles were moderately spaced, short, and roundly tapered in the rostral field (Fig. 9e). In the lateral fields, they often disappeared, and, if present, were conical (Fig. 9e).

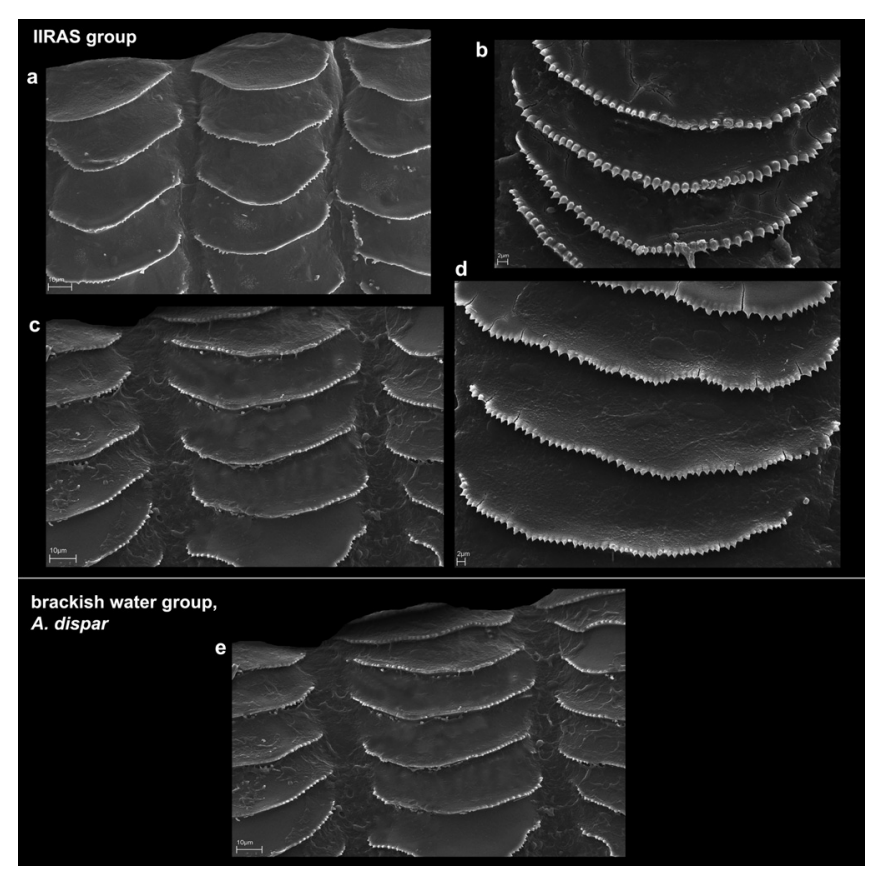

Figure 9. Patterns and shape of lepidonts present in anterior part of the lateral field of the body key scales shown for the IIRAS group (a-d) and brackish water group (e). They are spaced and short-conical in $A$. farsicus (a), crowded, often short and rounded, while few are long and pointed conical in A. isfahanensis (b), moderately spaced and conical in A. sophiae (c), often disappeared; if present conical A. vladykovi (d), crowded, short and rounded in A. dispar (e).

\section{Phylogenetic relationships}

Maximum-likelihood analysis indicated that the two groups (i.e., IIRAS and brackish water) of Aphanius species studied exhibited basal divergence, in which a brackish water species, $A$. dispar, formed a sister group with the IIRAS group. Among the IIRAS group, A. vladykovi showed the earlier divergence. A. isfahanensis was a sister to a clade containing A. farsicus from the Lake Maharlu Basin plus A. sophiae from the Kor River Basin (see the right side in Fig. 7).

\section{Discussion}

The objective of this study was to determine whether variation related to scale topology and scalar denticle morphology in the genus Aphanius was of taxonomic 
and phylogenetic significance. The use and value of scale morphology in fish taxonomy was recognized more than one hundred years ago when Agassiz (1833-1843) classified fishes on the basis of four scale types (i.e., "Les Placoides" - spine-like denticles of enamel and dentine, "Les Ganoides" thick plates of ganoine and bone, "Les Ctenoides" thin plates with comb-like posterior borders, and "Les Cycloide" - thin plates with smooth borders. However, since then and especially after the introduction and development of scanning electron microscopy, scale morphology has became more important in fish systematics, and it has been used widely in the taxonomy and phylogeny of different marine and freshwater fish groups (e.g., Hughes 1981, Lippitsch 1990, 1992, Roberts 1993, Jawad 2005, Gholami et al. 2013, Teimori 2016).

\section{Taxonomic values of scales in the genus Aphanius Nardo, 1827}

The major difference among the scales of the studied Aphanius species was related to their topology, so they can be classified according to the pattern on the outer edge in the posterior part. The brackish water species $A$. dispar had spined scales with spinous-like structures on the outer edge of the posterior region, while inland and inland-related Aphanius species (IIRAS) had cycloid scales with smooth outer edges in the posterior region. By performing multivariate analysis (CDA) on the morphometric variables of scales and shape analysis (CVA) on the seven landmarks on the scales, we were able to separate the members of the IIRAS group from the brackish water group. However, the comparative results of the four data sets examined indicated similar patterns of among-species differentiation when we compared scale morphometry and the phylogenetic tree. Despite this, there were differences when we compared them with the geometric morphometric method. Further investigation also indicated differences regarding of the shape of the scalar denticles. Within the IIRAS group, two lepidont morphotypes were observed, i.e., pointed and conical. Conical is the most common morphotype, which can be seen in the scales of $A$. farsicus, A. sophiae, and A. vladykovi. However, the most different types were observed in the scales of $A$. isfahanensis (pointed) from the Isfahan Basin, which was similar to the denticles observed in the scales of $A$. dispar, a brackish water species.

The taxonomic power of the scalar denticles, or lepidonts, has already been examined in fish taxonomy. Hollander (1986) documents the significance of characters related to the lepidonts in separating different poeciliid fishes. The taxonomic significance of lepidonts was also examined in cyprinodintid fishes and was found to be a useful tool for their taxonomy (Ferrito et al. 1998, 2001, 2003, Tigano et al. 2003). Ferrito et al. (2009) showed that the scale lepidonts of $A$. vladykovi (from the IIRAS group) and of $A$. ginaonis (from the brackish water group) were very similar. In spite of what Ferrito et al. (2009) reported, our results showed that lepidont morphology in the scales of $A$. isfahanensis is similar to that in A. dispar, and this results is supported by the recent study by Ba-Omar et al. (2013).

Based on the phylogenetic relationships among the studied Aphanius species, and also by taking into account the similar morphology seen in the scale lepidonts between $A$. dispar (a basal taxon in the phylogenetic tree) and $A$. isfahanensis (a member of the IIRAS group), it can be concluded that the presence of rounded lepidonts in members of the Aphanius species can be a primary state in their scales. Another possible explanation for the presence of rounded lepidonts in the Aphanius species is convergent evolution, which is the independent evolution of similar features (here rounded lepidonts) in species of different lineages. It should be noted that $A$. dispar and $A$. isfahanensis belong to two separate phylogenetic lineages (see the right side in Fig. 7).

Moreover, the general topology of the scale seems to vary among the studied Aphanius species. The brackish water Aphanius species in Iran ( $A$. dispar and $A$. ginaonis) have spined scales (Esmaeili and Gholami 2007; this study), while species of the IIRAS group have cycloid scales (this study). 
Additionally, the scales studied in A. sophiae and $A$. isfahanensis are polygonal and similar to those in $A$. dispar. A. dispar and A. ginaonis have a basal position in the phylogenetic trees of the genus Aphanius (Hrbek and Mayer 2003, Teimori et al. 2012). Therefore, it can be assumed that the polygonal state of the scales of Aphanius species is a primitive shared character state, which is probably inherited by the IIRAS group from the brackish water group.

Acknowledgments. This work received financial support from the Shahid Bahonar University of Kerman.

Author contributions. A.T and M.S.G did the analysis, and A.T. and M.M. wrote and edited the manuscript.

\section{References}

Agassiz J.L.R. 1833-1843 - Recherches sur les Poissons fossiles Neuchâtel - Petitpierre: 1-5.

Ba-Omar T.A., Al-Azri H., Al-Adawi K. 2013 - Scanning Electron Microscopical Study of the Aphanius dispar (Rüppell 1828) (Pisces: Cyprinodontidae) scales Micros. Microanal. 19: 116-117.

Bräger Z. 2016 - Scale Analysis of Mediterranean Teleosts Ph.D thesis, University of Pécs: 12 p.

Coad B.W. 2009 - A new species of tooth-carp, Aphanius mesopotamicus, from Iran and Iraq (Actinopterygii, Cyprinodontidae) - Zookeys 31: 149-163.

Edgar R.C. 2004 - MUSCLE: multiple sequence alignment with high accuracy and high throughput - Nucleic. Acids. Res. 32: 1792-1797.

Esmaeili H.R., Gholami Z. 2007 - Investigations on the surface ultrastructure of scale of Geno tooth-carp, Aphanius ginaonis (Holly, 1929) (Actinopterygii: Cyprinodontidae) using scanning electron microscope - Iran. J. Biol. 20: 307-314.

Esmaeili H.R., Teimori A., Gholami Z., Reichenbacher B. 2014 - Two new species of the tooth-carp Aphanius (Teleostei: Cyprinodontidae) and the evolutionary history of the Iranian inland and inland-related Aphanius species - Zootaxa 3786: 246-268.

Ferrito V., Ippolito S., Tigano C. 1998 - Microanalisi delle scaglie in tre specie del genere Aphanius Nardo (Teleostei, Cyprinodontidae), 59u Congresso dell'Unione Zoologica Italiana, S. Benedetto del Tronto (AP): 60 p.

Ferrito V., Tigano C., Corsaro M. 2001 - Comparative investigation on the microstructure of the scale in Lebias Goldfuss species (Teleostei, Cyprinodontidae). X European Congress of Ichthyology, Praga.
Ferrito V., Corsaro M., Tigano C. 2003 - Scale surface morphology in Lebias, Goldfuss, 1820 (Teleostei, Cyprinodontidae) - J. Nat. Hist. 37: 1529-1534.

Ferrito V., Papplardo A.M., Fruciano C., Tigano C. 2009 Morphology of scale lepidonts in genus Aphanius (Teleostei: Caprinodontidae) using scanning electron microscopy - Ital. J. Zool. 76: 173-178.

Gholami Z., Teimori A., Esmaeili H.R., Schulz-Mirbach T., Reichenbacher B. 2013 - Scale surface microstructure and scale size in the tooth-carp genus Aphanius (Teleostei, Cyprinodontidae) from endorheic basins in Southwest Iran - Zootaxa 3619: 467-490.

Gholami Z., Esmaeili H.R., Erpenbeck D., Reichenbacher B. 2014 - Phylogenetic analysis of Aphanius from the endorheic Kor River Basin in the Zagros Mountains, Southwestern Iran (Teleostei: Cyprinodontiformes: Cyprinodontidae) - J. Zool. Syst. Evol. Res. 52: 130-141.

Gouy M., Guindon S., Gascuel O. 2010 - SeaView Version 4: a multiplatform graphical user interface for sequence alignment and phylogenetic tree building - Mol. Biol. Evol. 27: 221-224.

Hammer Ø., Harper D.A.T., Ryan P.D. 2001 PAleontological STatistics Software Package For Education And Data Analysis - Palaeontol. Electron. 4: 1-9.

Hrbek T., Meyer A. 2003 - Closing of the Tethys Sea and the phylogeny of Eurasian killifishes (Cyprinodontiformes: Cyprinodontidae) - J. Evol. Biol. 16: 17-36.

Hrbek T., Keivany Y., Coad B.W. 2006 - New species of Aphanius (Teleostei, Cyprinodontidae) from Isfahan Province of Iran and a reanalysis of other Iranian species - Copeia 2: 244-255.

Hollander R.R.1986 - Microanalysis of scales of poeciliid fishes - Copeia 1: 86-91.

Hughes D.R.1981 - Development and organization of the posterior field of ctenoid scales in the Platycephalidae Copeia 1981: 596-606.

Ibańez A.L., Gutiérrez-Benítez O. 2004 - Climatie variables and spawning migrations of the striped mullet and white mullet in the north-western area of the Gulf of Mexico - J. Fish Biol. 65: 822-831.

Jawad L.A. 2005 - Comparative scale morphology and squamation patterns in triplefins (Pisces: Teleostei: Perciformes: Tripterygiidae) - Tuhinga 16: 137-167.

Johal M.S., Esmaeili H.R., Sharma M.L. 2006 - Scale structure of a cobitid fish, Cobitis linea (Haeckel, 1849) using different modes of SEM - Curr. Sci. 91: 1444-1446.

Klingenberg C.P. 2011 - MorphoJ: an integrated software package for geometric morphometrics - Mol. Ecol. Resour. 11: 353-357.

Lippitsch E. 1990 - Scale morphology and squamation pattern in cichlids (Teleostei, Perciformes): A comparative study - J. Fish Biol. 37: 265-291.

Lippitsch E. 1992 - Squamation and scale character stability in cichlids, examined in Sarotheroden galilaeus 
(Linnaeus, 1758) (Perciformes, Cichlidae) - J. Fish Biol. 41: 355-362.

Requieron E. A., Torres M.A.J., Demayo C.G. 2012 - Applications of Relative Warp Analysis in Describing of Scale Shape Morphology Between Sexes of the Snakehead Fish Channastriata - IJBEES, 1: 205-209.

Roberts C.D. 1993 - Comparative morphology of spined scales and their phylogenetic significance in the teleostei - Bull. Mar. Sci. 52: 60-113.

Rohlf F.J. 1990 - Morphometrics - Annu. Rev. Ecol. Syst. 21: 299-316.

Rohlf F.J. 2013 - tpsDig. digitize landmarks and outlines Department of Ecology and Evolution, State University of New York at Stony Brook.

Rohlf F.J. 2015 - tpsUtil. file utility program - Department of Ecology and Evolution, State University of New York at Stony Brook.

Schneider C.A., Rasband W.S., Eliceiri K.W. 2012 - NIH Image to ImageJ: 25 years of image analysis - Nat. Methods 9: 671-675

Stamatakis A. 2006 - RAxML-VI-HPC: maximum likelihood-based phylogenetic analyses with thousands of taxa and mixed models - Bioinformatics 22: 2688-2690.

Teimori A. 2016 - Scanning electron microscopy of scale and body morphology as taxonomic characteristics of two closely related cyprinid species of genus Capoeta Valenciennes, 1842 in southern Iran - Curr. Sci. 111: 1214-1219.

Teimori A., Esmaeili H.R., Gholami Z., Zarei N., Reichenbacher B. 2012a - Aphanius arakensis, a new species of tooth-carp (Actinopterygii, Cyprinodontidae) from the endorheic Namak Lake basin in Iran - Zookeys 215: 55-76.

Teimori A., Schulz-Mirbach T., Esmaeili H.R., Reichenbacher B. 2012b - Geographical differentiation of Aphanius dispar (Teleostei: Cyprinodontidae) from Southern Iran J. Zool. Syst. Evol. Res. 50: 289-304.

Teimori A., Esmaeili H.R., Erpenbeck D., Reichenbacher B. 2014 - A new and unique species of the genus Aphanius (Teleostei: Cyprinodontidae) from Southern Iran: A case of regressive evolution - Zool. Anz. 253: 327-337.

Tigano C., Ferrito V., Pappalardo A.M., Corsaro M. 2003 Studio comparativo della microstruttura delle scaglie al SEM. Contributo alla filogenesi del genere Lebias In: $34 \mathrm{u}$ Congresso S.I.B.M.; 31 maggio-6 giugno; Port al Kantaoui, Tunisia.

Zelditch M.L., Swiderski D.L., Sheets H.D., Fink W.L. 2004 Geometric Morphometrics of Biologists: A Primer Elsevier Academic Press, San Diego: 443 p. 